\title{
浅谈高校教师研究性备课策略一以《小学语文教学与研究》课 程为例
}

潘胜男

商丘学院人文学院

DOI:10.32629/er.v3i2.2504

[摘 要] 课堂如何吸引学生的关注,提高学生的课堂参与性是高校教师们亟待解决的问题。清源正本,教师应开展研究性备课。文章以商丘学 院小学教育专业《小学语文教学与研究》课程为例,为读者介绍研究性备课五步法,第一以全面研究培养方案和教学大纲为依托,制定科学的教 学计划; 第二研究教学对象, 做好学情分析; 第三详备教学资源, 择选教学内容; 第四丰富教学方式, 融汇教法学法; 第五重视教学反思对高校 教师专业成长的翼助。

[关键词] 教学大纲; 学情; 教学资源; 教学方法; 教学反思

The Strategy of Research course preparation for Teachers in Colleges and Universities-—Taking the course of Chinese Teaching and Research in Primary Schools as an example

Pan Shengnan

Humanities,Shangqiu College,Shangqiu, Henan

[Abstract] how to attract students' attention and improve students' classroom participation is an urgent problem for university teachers to solve. In the original of Qingyuan, teachers should carry out research to prepare lessons. Taking the course of Chinese Teaching and Research in Primary School of Shangqiu College as an example, this paper introduces the five-step method of preparing courses for readers. First, based on the comprehensive research and training scheme and syllabus, the scientific teaching plan is worked out; the second research object is to do a good job in the analysis of learning situation; the third is to prepare the teaching resources and choose the teaching content; the fourth enriches the teaching methods and integrates the teaching methods. The fifth is to attach importance to the teaching reflection on the professional growth of university teachers.

[Key words] syllabus; learning situation; teaching resources; teaching methods; teaching reflection

高校课堂 “低头族” 现象普遍, 学生上课不积极, 课堂参与度低。为解 决此问题, 多数高校推行 “无手机课堂” 的措施。即在教室门口放置带有 数字标识的方形布袋, 上课前, 学生将手机关机并放置在布袋里。其措施曾 在微博上引起学生的热烈讨论:

学生甲: 很好! 首先, 解决了学生上课玩手机的情况, 使其有了专心听 课的准备; 其次, 教师没有了监测学生玩手机的顾虑, 专心于课堂教学; 最 后, 给师生的教学互动营造了良好的氛围。心无旁鷔,才能专注。

学生乙: 一边上课一边查资料, 及时弥补不知道的知识点。没有手机, 上课就变成单向信息接收, 没有证实证伪, 觉得差了点什么。

学生丙: 难道不是应该思考如何把学生的注意力吸引到课堂上吗?

学生丁: 治标不治本! 老师课讲的好学生自然会听。

学生戊: 有手机就玩手机, 没有手机就睡觉。

(......

由此可见, “无手机课堂” 并未真正解决问题。如何吸引学生, 使其积 极主动地参与到教学中, 关键在于课堂教学的高效性。备课是教学的前提, 因而高校课堂 “活” 起来的有效策略是教师开展研究性备课。

\section{1 知悉培养方案和教学大纲,制定教学计划}

培养方案设定了本科生在校四年的培养目标和培养规格。同时规定了 开课计划和考核方式, 以及理论和实践教学环节的比例。教学大纲则重点 突出课程的性质与目标, 详细阐述课程的教学重难点。高校教师在讲授新 课前务必熟知培养方案和教学大纲, 从而制定科学合理的教学计划。以商 丘学院小学教育专业的本科生为例 (下同), 教师执教《小学语文教学与研
究》时, 首先通过培养方案了解其理论 (24课时) 与实践学时 (8课时); 接着 研读教学大纲和教材, 通过其章节目标、重难点做出学时安排。该课程选 取的教材为吴忠豪的《小学语文课程与教学》 (第二版), 主要内容为: 小 学语文课程标准, 小学语文教材, 识字、写字教学, 阅读教学, 习作教学, 口 语交际教学, 综合性学习和学业评价。教材每一章都有学时建议, 通过与培 养方案结合进行调整, 最终确定学时, 具体情况如表 1 :

表1 商丘学院《小学语文教学与研究》学时分配表

\begin{tabular}{|c|c|c|c|}
\hline 章节 & 主要内容 & 理论学时分配 & 实践学时分配 \\
\hline 第一章 & 小学语文课程标准 & 2 & 0 \\
\hline 第二章 & 小学语文教材 & 2 & 0 \\
\hline 第三章 & 识字、写字教学 & 2 & 2 \\
\hline 第四章 & 阅读教学 & 4 & 2 \\
\hline 第五章 & 习作教学 & 4 & 2 \\
\hline 第六章 & 口语交际教学 & 2 & 2 \\
\hline 第七章 & 语文综合性学习 & 4 & 0 \\
\hline 第八章 & 语文学业评价 & 4 & 0 \\
\hline & 合计 & 24 & 8 \\
\hline
\end{tabular}

教师制定好教学计划后, 以此为备课的主要依据, 确定教学内容的详 略。根据学生学情, 选择适当的教学方法进行备课。 


\section{2 研究教学对象,做好学情分析}

学情分析是研究性备课不可忽略的重点, 教师分析学情首先要了解教 学对象, 知其优缺点。该课程开设在第三学期, 即大二上学期。二年级的学 生已有一年级的学习作为基础, 并且先修了《课程与教学论》。因此继续学 习《小学语文教学与研究》课程具有一定的优势。但因其并未承接小学语 文的实际教学任务, 所以在学习的过程中无法深入理解小学生的学习需求, 其教学设计或无法满足真实的课堂需要。这要求高校教师在进行该课程的 教学时, 应尽可能为学生创设实践教学情境。如观看小学语文课堂实录的 视频、进行课堂模拟教学、去小学进行听课等。

教师备课时还应注意以下两点: 第一, 充分了解学生的学习兴趣。兴 趣是最好的老师, 只有深入了解学生的学习兴趣, 有针对性地用充实的内 容来吸引学生, 学生的注意力才能长久维持 ${ }^{[1]}$ 。美国弗吉尼亚潮水社区学 院的物理教授大卫・莱特为了引起学生的兴趣, 在课堂上做冰淇淋、躺钉 板……学生在欢乐的氛围中积极参与, 受益匪浅。《小学语文教学与研究》 课堂可借鉴大卫・莱特教授的经验, 让学生乐于学习。如通过剖析学生感 兴趣的教学案例进行教学技能的融会贯通; 亦可把《小学语文教学与研究》 课程与《小学美术教学与研究》、《小学音乐教学与研究》等课程进行结合。 以汉语拼音教学设计的学习为例, 可以在其中加入《拼音儿歌》的内容, 教师在课堂上可以教学生歌唱, 以便小学生记忆; 又如识字教学设计的学 习, 在设计 “日、月、山、水……”等象形字时的识字方法时, 教师可引导 学生与绘画相结合 ${ }^{[2]}$; 第二, 满足学生的学习需求。学生是学习的主体, 因 此教师的教学应以学生为本位, 立足于学生的长远发展。《小学语文教学与 研究》课程不仅要教会学生如何进行教学设计, 更应教给学生如何终身学 习, 接受不断发展的教学需求, 以及如何应对课堂突发事件等。

\section{3 祥备教学资源,择选教学内容}

对于大学生来说教材只是一本学习参考书, 他们需要学习的内容更多 的是教材之外的知识。高校教师无法像初高中教师那样一篇接一篇讲解文 章的知识点, 而应把关注点放在学生对知识的理解、分析解决问题能力的 提升, 以及学生对拓展知识的渴求 ${ }^{[3]}$ 。因此高校教师在备教材时, 应做好对 教材的 “用、增、删、合、创” ${ }^{[4]}$ 。

如吴忠豪《小学语文课程与教学》(第二版) 教材重在讲解如何教会学 生进行教学设计, 并附有大量的教学设计案例。但教学设计只是上课的前 期准备工作, 在实际的小学语文教学过程中, 无法忽略课堂的突发事件。因 此不能单一地交给学生如何写教案, 更应让他们学习当课堂突发预设之外 的情况时应如何处理。此外学生还需了解最新的教学理念和每一阶段学生 应重点掌握的技能。因此教师在备课时便要考虑到学生的这一学习需求, 对教材的内容进行增添; 但若一味增添内容, 亦会为学生带来识记的负担, 因此对教材内容进行删减也是教师备课时应注意的问题。该教材的最大特 点是语言文字通俗易懂, 内容详细。有些内容是学生非常熟悉的, 因此教师 在备课时可不作为重点, 让学生课下自学即可。

众多周知, 高校教师会为学生推荐一些与本课程有关的书籍或者期刊 文献。教师在备课时也可把这些学习资料与所用教材相联系。《小学语文课 程与教学》可与同作者的《小学语文课程与教学论》进行结合, 分析探究其 异同点, 择选最合适的内容进行备课。同时, 教师通过阅读最新的文献资料, 把教材与新时代的课程教学理念结合; 基于教材, 不拘泥于教材是高校教师 研究性备课的基本原则之一。《小学语文课程与教学》按照章节的形式进行 编排, 形式规整。每一章分为四小节, 第三章至第七章按照 “改革试验、基 本原则、教学策略、教学技能” 的方式进行。学习其中一章便知道其余四 章如何进行教学, 易造成教与学的疲崽感。因此任课教师可采用专题的形式 进行教学, 打破教材原有的编排方式, 讲解学生最需要和最想了解的内容。

\section{4 丰富教学方式,融合教法学法}

学生是学习活动的主体, 高校课堂 “活” 起来的重要举措是使学生积 极参与到教学活动中。高校教师应采取多种教学方式, 丰富教学方法。利 用网络教学平台吸引学生的兴趣, 结合翻转课堂提升学生的自主、合作、 探究学习的能力, 同时鼓励学生开展模拟课堂教学活动, 促进其对课堂的 掌控 ${ }^{[5]}$ 。

如《小学语文课程与教学》第三章 “小学语文识字、写字教学” 的第 一节中关于识字、写字众多改革试验的内容, 可以采用小组合作的形式进 行课下的整理与学习, 在课堂上分享本组的研究成果。这一方式不仅锻炼 了学生自主学习的能力, 也培养了学生的团队合作意识, 以及发现问题、解 决问题的能力; 在进行教学设计的学习时, 可以让学生根据自己的教学设 计开展小学语文的课堂模拟教学活动。大学生化身为小学语文教师, 同学 配合变身为充满童趣的小学生, 由此进行一堂别开生面的教学活动。但高 校教师在进行模拟课堂备课时, 需注意对大学生学习心理的指导, 使他们 能放开同班同学身份的束缚, 真正模拟小学课堂; 此外, 科技打破了时空的 局限, 教师可为学生准备优质教学视频供学生学习参考。科学技术的进步 亦进一步丰富了教学的方式, 大量的网络教学平台应运而出。高校教师在 备课时可充分利用网络学习平台进行教学方式的创新。以超星学习通和 《小学语文教学与研究》课程相结合为例, 教师可先通过学习通上传学习 资源, 让学生课下进行学习, 课堂上可直接对学习资源的内容进行探讨研 究, 大大提高了课堂教学的效率。另外, 亦可在学习通上布置作业, 采取生 生评阅的方式, 既减轻教师的教学压力, 又有助于学生巩固所学知识。进一 步发布讨论话题, 对作业中的疑难问题进行相互探讨, 教师通过学生的讨 论能更好地了解学生的想法 ${ }^{[6]}$ 。

\section{5 持备教学反思,促进专业成长}

备课不是一次就能完成的, 它的任务不仅是完成本节课的教学任务, 更是为提高教学效果精益求精。因此, 研究性备课一定要重视课后反思, 不断更新完善教学反思。反思是教师教学设计进步的桥梁。只有反思才能 知道自己教学过程中的不足, 意识到不足才会有所改进, 从而提升下次的 教学效果 ${ }^{[7]}$ 。

首先记录学生在课堂上的思维火花 ${ }^{[8]}$ 。教师备课只是一项预设的教学 活动。实际的课堂教学充满了可变性。有些内容教师备课时没有考虑到, 但学生出其不意的提问使其得到丰富与发展。这些问题是丰富的教学资源, 教师课后应第一时间进行记录。如在进行拼音《 $a \quad 0 \quad$ e 》的教学时, 教师 指出 “o” 现在拼作ou。学生感到很诧异, 因其上学时拼作uo, 于是有学生 提问 “bo” 怎么拼读。而这个问题执教老师备课时没有注意到。因此让学 生利用网络搜集资料, 进行讨论。通过讨论, 学生比较信服的结论为: 普通 话里面o是不能作韵母的。必须有一个介音u在前面引导。而bo/ po / mo / fo这样拼写的原因是 $b, p, m$ 和 $f$ 都是唇音。这些唇音和o相拼时, 讲普通话 的人会在习惯上给o加一个圆唇的效果（也就是o变成了uo）。所以汉语拼音 方案里 $b, p, m$ 和 $f$ 和 $o$ 相拼时没有在 $o$ 前加 $u$ 这个介音。o在拼音里是元音, 所有 元音都是唇自然微张不动的。在发 0 的时候短音 “哦窝” 才是最正确的 ${ }^{[9]}$ 。

其次反思教法学法的使用。课堂教学是否成功, 教师自身有着深刻的体 会。对于实际教学活动中, 教学方法的选用是否适当可以通过课堂体现出 来。如小组合作学习虽有利于培养学生的合作意识, 减轻学习压力, 但并不 是适用于所有情况。如教师在布置习作教学设计作业时, 让小组合作进行。 具体的步骤为: 小组讨论, 确定教学目标、重难点、教法学法、教学过程; 然后小组成员分工, 进行教学设计的撰写。但在实际的操作过程中, 仅有一 两个小组是讨论后撰写教学设计, 多数小组成员采取独自进行的方式, 相互 之间很少沟通, 因此提交的教学设计中存在着环节衔接不良的问题。 


\section{学前舞蹈教学中所存在的问题与解决对策研究}

刘宇

青海柴达木职业技术学院

DOI:10.32629/er.v3i2.2439

[摘 要] 现阶段,我国高职院校的教学模式也正在面临着改革与创新,对于高职院校学前舞蹈专业来说,在展开教学的过程中,应该注意对学生 自身的实践技能水平进行提升。从现阶段我国很大一部分高职院校学前舞蹈专业教学展开的实际情况来看,往往还存在着一定的问题,这也导致 了高校专业课程教学质量受到了一定的影响,本文尝试对解决问题的对策进行了探讨分析。

[关键词] 学前舞蹈教学; 问题; 解决措施

对于职业教育来说, 其重要作用是为了培养行业人才, 因此, 要注重对 学生自身的实践技能水平进行提升。舞蹈是很多高等院校学前教育专业中 的必修课, 主要是与舞蹈这种艺术形式自身的属性有直接关系, 学前舞蹈 不仅可以锻炼孩子自身的身体协调能力, 同时也可以使孩子的意志力得到 提升。从现阶段我国很多高等职业院校在展开舞蹈学前教育教学的情况来 看, 尚且还存在着一定的问题, 这也直接导致了最终的教学效果并不十分 理想, 学生的课堂参与度较低, 这与教师自身的教学模式选择以及应用有 直接关系。想要使得大学生自身的学前教育水平得到全面提升, 学前舞蹈 素质是最为基本的专业素质之一。高校方面应该对教育教学的理念进行深 化改革, 本次以学前舞蹈专业教学为例, 对教学过程中存在的问题进行了 探讨分析。

\section{1 高职院校学前专业舞蹈实践技能教学的重要性}

1. 1 巩固了学生舞蹈专业的理论知识

从舞蹈理论来看, 主要会涉及到常识、概念、特点以及分类等几个方 面, 在对舞蹈进行编创的时候, 还应该考虑到构图、灯光、舞台以及音乐等 几个方面, 教师在展开教学的时候如果只是应用传统单一讲述的方式往往 很难激发学生的学习兴趣, 会使学生感觉到课堂学习存在一定难度, 学习 效率也势必会受到一定的影响 ${ }^{[1]}$ 。因此, 教师在展开教学活动的时候应该 注意将理论知识与实践知识进行结合, 通过实践操作的方式来促进学生对 基本知识点进行理解, 这样有利于学生对知识点进行更好的消化。舞蹈理

高效课堂的开展离不开以上五个环节的研究性备课。研究性备课要求 教师把备课贯穿于课堂教学的始终: 课前做好预设, 课中及时更换策略, 课后做好教学反思 ${ }^{[10]}$ 。循环往复, 教师对经验的不断总结, 促进教师持续的 专业性成长。

\section{[参考文献]}

[1]曾文婕. “备学生” 新论[J].中国教育学刊,2013,(3):46-50.

[2]雷文英.小学语文趣味识字教学探究[C].中国教育发展战略学会教 育教学创新专业委员会.2019 全国教育教学创新与发展高端论坛论文集 (卷二).中国教育发展战略学会教育教学创新专业委员会: 中国教育发展战 略学会教育教学创新专业委员会,2019:59-60.

[3]张义红.高校教师备课的“六部曲” [J].广东虫业,2018,(11):70-71

[4]文振华,李启璘,杨红普.关于高校教师备课的几点思考 [J].新课程 研究:下旬,2019,(4):77-79.

[5]杨慧. “互联网 + ”背景下混合教学模式的研究与实践 [J].科教文汇 (下旬刊),2019,(11):100-103.

[6]余梅.基于超星学习通平台的国际金融课程线上线下交互教学系
论知识与实践技能的相互融合以及转变让我们看到了舞蹈实践技能结合 以及创新的重要性, 同时实践技能也是提升学生自身综合技术水平的重要 渠道。

\section{2 激发了学生对舞蹈学习的兴趣}

从现阶段学前舞蹈专业的学生学习情况来看, 很多学生往往对课堂教 学活动中所涉及到的内容并不十分感兴趣, 很难积极主动的融入到学习氛 围当中。但是有很大一部分学生对音乐以及构图等较为感兴趣, 但是这些 学生对传统的课堂教学方面重视程度并不高, 因此, 教师要注意对学生自 身的学习兴趣进行提升, 教师应该注意积极设定动手操作的环节, 这是非 常关键的, 在操作的过程中教师应该做好引导工作。教师要充分挖掘学生 擅长的方面, 以实践活动的方式引导学生可以使学生对舞蹈学习产生较为 浓厚的兴趣, 这也为未来的学习以及努力规划了方向 ${ }^{[2]}$ 。

\section{2 学前教育专业舞蹈教学中存在的问题}

2. 1 教材存在不适用的情况

从现阶段我国高职院校学前教育专业舞蹈教育活动展开的实际情况 来看, 尚且存在这教材不适用的情况。对于舞蹈来说, 不仅是一门艺术学科, 同时也是经验学科的一种, 规范的、实用性强的教材是保证这门学科教学 质量的关键。但是目前来看, 很多教师只是自编了简单的教材来展开教学 活动, 这也势必会对最终的教学的综合品质产生一定的影响。还有一些教 师干脆应用舞蹈专业教材来展开教学活动。但是实际上这两种教材都不适

[7]耿红卫,潘胜男.研究性备课是教师专业成长的起点 [J]. 基础教育论 坛,2019,(2):28-30.

[8]李林浩.关于高校教师应如何 “上好课”的思考 [J]. 文教资 料,2013,(14):160-161+174.

[9]高天.基于 praat 的单韵母 “0”的音值分析[J].现代语文(语言研究 版),2014,(8):29-31.

[10]吴枝兵,彭鸿雁,朱宏.地方应用型高校教师教学投入情况调查研 究[J].齐鲁师范学院学报,2018,33(05):7-18.

作者简介:

潘胜男 (1993--), 女, 汉族, 河南永城人, 商丘学院人文学院助教, 教 育学硕士研究生, 主要从事语文课程与教学研究

项目:

2019年度商丘学院校级课题: 研究性备课: 高校教师专业成长的 起点(2019-KYC-10)。

该课程为商丘学院小学教育专业本科生的专业课,使用教材为吴 忠豪《小学语文课程与教学》(第二版)。 